\title{
Requirements for Performance Management Systems: A Delineation of the Comprehensive Set of Criteria
}

\author{
Bartłomiej NITA*
}

\section{Introduction}

There are organizations which have serious problems with transforming their strategies in-to actions and achieving good performance, so the major purpose of modern management accounting is to support the strategy execution. However, for fulfilling this goal it is essential to design and implement effective performance measurement and management system in order to asses, control, and finally improve organizational performance. Unfortunately, still a lot of companies today use financial and accounting-based calculations as the ultimate measures of company performance although exclusively financial approach to performance is not sufficient any longer.

The aim of the paper is to figure out the requirements that should be fulfilled by modern performance management systems. Thus, in the first part of the article the short review of contemporary approach to performance management was described, in the following part different opinions and discussions from the relevant academic literature were depicted and finally the comprehensive set of ten requirements was proposed.

\section{Contemporary Approach to Performance Management}

In 1965 R. N. Anthony published his seminal work titled "Planning and Control Systems", in which he introduced the concept of management control. His classic definition of management control was "the process by

Bartłomiej Nita, Ph.D. - Assistant Professor; Department of Managerial Accounting and Accounting for Management, Institute of Accounting, Faculty of Management, Computer Science and Finance, Wrocław University of Economics, ul. Komandorska 118/120, 53-345 Wrocław, Poland; <bartlomiej.nita@ue.wroc.pl>. 
which managers assure that resources are obtained and used effectively and efficiently in the accomplishment of the organizations' objectives" (Anthony, 1965, p. 17). Over many years together with his co-workers he further developed this idea, and in one of latest books he claims that management control is "the process by which managers influence other members of the organization to implement the organization's strategies" (Anthony - Govindarajan, 2004, p. 7). While developing his own definition, R.N. Anthony adds that management control involves a variety of activities, including (Anthony - Govindarajan, 2004, p. 7):

1. planning what the organization should do,

2. coordinating the activities of several parts of the organization,

3. communicating information,

4. evaluating information,

5. deciding what, if any, action should be taken,

6. influencing people to change their behavior.

The Anthony's approach to management control influenced the subsequent development in this area, however it triggered off a lot of discussions and controversies. According to Otley (1999, p. 364) that approach was intended to broaden the scope of information being considered beyond just accounting information. Paradoxically, it was largely unsuccessful in achieving this, mainly because of its deliberate neglect of operational control. Operational control was neglected because it was apparent that different organizations used very different practices at the operating level, so Anthony concentrated on the commonalties that existed between them. Focusing on commonalties allowed the use of a common language capable of including all organizational activities. Accounting provided such a language and management control became largely synonymous with management accounting at a time when this discipline of management accounting was in almost terminal decline.

Another objection to this view comes from the belief that it is now becoming more common for lower levels employees to be actively involved, not only in the day-to-day operations that were once the domain of middle and senior managers, but in activities that are of strategic significance. Thus - as Langfield-Smith claims (1997, p. 209) - the artificial boundaries between operations, managerial, and strategic control may no longer hold. 
The 1980s were very important from the point of view of the evolution of management accounting and performance management. On the one hand that period closed lasting from the 1950s stagnation in the process of the formation of new methods on the other hand it presaged the dynamic expansion of performance measurement techniques. Thus 1980s can be perceived as a transitional period, in which a lot of postulates referring to the change in management control occurred. During that time globalization processes all over the world intensified and the market conditions and economic environment were getting more and more competitive especially due to increasing deregulation of global markets. The comparison of the biggest world economies indicated that American companies' performances were rather weak in relation to Japanese and western European companies ${ }^{1}$.

Taking into account the factors limiting the achievement of satisfactory performance by American enterprises, R. S. Kaplan clearly indicated the need to introduce nonfinancial measures under the framework of management accounting. He analyzed the diffusion of Japanese management techniques into the practice of American companies at the turn of the 1970s and 1980s through a lot of examples of companies such as General Motors, Ford, Motorola and Hewlett-Packard. The given examples suggest that significant savings in the US environment with US workers can be achieved by means of the attention to quality control and reduced inventory. Thus he proposed three major nonfinancial factors to be taken into consideration while assessing corporate performance: quality, inventory and productivity (Kaplan, 1983, p. 689).

Shortly after that notion R. S. Kaplan put a proposition about the discrepancy between innovations that occurred in business and innovations that occurred in academic institutions (Kaplan, 1984, p. 406). He strongly articulated the opinion that the challenges of the competitive

1 In 1980 R. H. Hayes and W. J. Abernathy claimed that during the past several years American business had experienced a market deterioration of competitive vigor and a growing unease about its overall economic well-being. That decline had been attributed to the rapacity of OPEC, deficiencies in government tax and monetary policies and the proliferation of regulation. The authors added to those factors that American managers had increasingly relied on principles which prized analytical detachment and methodological elegance over insight, based on experience, into the subtleties and complexities of strategic decisions. As a result, maximum short-term financial returns had become the overriding criteria for many companies (Hayes Abernathy, 1980, p. 70). 
environment in the 1980s should have caused reexamination of traditional cost accounting and control systems. Virtually all of the practices employed by companies that time had been developed by 1925. Despite considerable change in the nature of organizations between 1925 and 1980 s, there had been little innovations in the design and implementation of cost accounting and management control systems (Kaplan, 1984, p. 390).

R. S. Kaplan kept continuing his research together with H. T. Johnson and in their work "Relevance Lost" they announced thesis about lost usefulness of management accounting for decision making purposes. From the point of view of performance measurement they maintained that management accounting systems in use led to the distorted product costs, delayed and overly aggregated process control information, and shortterm financial measures that did not reflect the increases or decreases in the organization's economic position (Johnson - Kaplan 1987, p. 13).

At the beginning of the 1990s R. G. Eccles (1991) published an article, in which he predicted the revolution in corporate performance measurement area. He claimed that in the heart of that revolution lied a radical decision involving the shift from treating financial figures as the foundation for performance measurement to treating them as one among a broader set of measures. Eccles indicated the need for increasing the set of performance measures and adjusting them to managers' expectations. $\mathrm{He}$ also argued that this kind of revolution never ends and he was not talking about changing basis of performance measurement from financial statistics to something else. The whole idea forces the performance measurement to be an ongoing, evolving process.

The evolution of performance measurement at the turn of the century went beyond the considerations on nonfinancial measures. In the last decade of the twentieth century the strategic focus of management accounting emerged and a lot of new management accounting methods which were proposed with respect to strategic management. As a result the notion of strategic management accounting was further developed ${ }^{2}$.

2 The term "strategic management accounting" was coined by K. Simmonds in 1981 who depicted strategic management accounting as "the provision and analysis of management accounting data about a business and its components which is of use in the development and monitoring of the strategy of that business" (Simmonds, 1981, p. 26). 
Nita, B.: Requirements for Performance Management Systems: A Delineation of the Comprehensice Set of Criteria.

Nowadays management accounting methods concentrate heavily on strategy, shareholders' wealth and intangible assets. Thus it is possible to distinguish three major areas of research in the context of performance measurement:

1. performance measurement methods oriented toward shareholders' value creation,

2. intangible assets and intellectual capital measurement methods,

3. multidimensional scorecards and dashboards.

The formation of measurement methods oriented toward value creation was determined by the reorientation of corporate objectives that started in the 1980s and led to the acceptance of shareholders' value paradigm. One of the first proponents of this approach was A. Rappaport who distinguished seven generic value drivers and depicted the relationships among them and value ${ }^{3}$. Value-based management and its linkages with management accounting caused the rapid development of performance measurement methods in the context of shareholders' wealth.

The evaluation of tangible sources of value creation and financial quantification of benefits generated within the company is not sufficient. It is now widely believed that focus on intellectual capital and intangible assets provides real business value. This is the reason for searching new approaches to corporate performance measurement and assessment.

B. Marr et al. (2003, p. 443) through the systematic literature review were able to identify five main reasons for measuring intellectual capital and intangible assets:

1. to help organizations to formulate their strategy,

2. assess strategy execution,

3. assist in diversification and expansion decisions,

4. use these as a basis for compensation,

5. to communicate measures to external stakeholders.

3 A. Rappaport as early as in 1981 proposed the methodology of cash flow estimation for the purposes of different strategic options evaluation form the point of view of value creation (Rappaport, 1981) and later he published a comprehensive book on value creation (Rappaport, 1986). 
The last one and most advanced modern approach to measuring corporate performance is the usage of multidimensional scorecards. In the early 1990s, the Nolan Norton Institute, the research arm of KPMG, sponsored a study titled "Measuring Performance in the Organization of the Future". D. Norton, chief executive officer of Nolan Norton, served as the study leader and Robert Kaplan as an academic consultant from Harvard University. After a yearlong research program with twelve companies, the study group proposed a comprehensive framework, named the "balanced scorecard". The aim of the this approach was to give managers a comprehensive view of the business using both financial and nonfinancial, as well as short-term and long-term performance measures ${ }^{4}$. Nowadays the aim of balanced scorecard is to allow managers to focus on the critical areas, driving the organization's strategy forward. Thus this method is perceived not only as a measurement tool, but also as a strategic management framework and method for implementing organizational strategy and - as Kaplan and Norton claim - a tool of "building strategy-focused organization" (Kaplan \& Norton 1996, 2001).

\section{Literature Review of Requirements for Performance Management Systems}

Both the choice of appropriate approach to performance management and the evaluation of existing solutions need the list of criteria to be specified that can be used as a reference set of requirements. Different authors put an emphasis on various requirements that should be fulfilled by modern performance management systems. Thus, the original proposition of comprehensive set of such criteria is followed by brief review of opinions and discussions from the relevant academic literature.

B. Maskell $(1989$, p. 33) claims very strongly that the traditional performance measures are inadequate and sometimes misleading. They are inflexible, very often too late to be effective, usually expressed in irrelevant financial terms and are not directly related to the company's strategy. So under the framework of world class manufacturing $\mathrm{WCM}^{5}$ he

4 The first article on the balanced scorecard was published in 1992. See: (Kaplan Norton, 1992).

5 The term "world class manufacturing" was proposed by R. Schonberger in his book (1986). This concept concentrates on management techniques oriented towards improvement in manufacturing and refers to quality measurement, delivery time, production flexibility, just-in-time, six sigma, TQM, benchmarking etc. 
identifies seven common characteristics of performance measures and performance management systems:

- directly related to the manufacturing strategy,

- non-financial measures,

- vary between locations,

- change over time,

- simple and easy to use,

- fast feedback,

- intended to tech rather to monitor.

M. E. Beischel and K. R. Smith (1991, p. 25-26) offer a framework for measuring manufacturing performance based on two basic premises. In their opinion first step is to establish critical success factors, items so important to the company that, without any one of them, the company would fail ${ }^{6}$. Certain factors are universal to all manufacturing companies and they distinguish quality, customer service, resource management, cost, and flexibility. Second, all manufacturing measures at all organization levels should be linked to ensure constancy of purpose among organizational levels and to point to cause-and-effect relationships so all employees can solve the problems that cause poor performance and continue practices that cause good performance.

M. W. Grady (1991, p. 49) expresses a belief that in most companies business strategy is set by senior management behind closed doors. Technical and functional management usually does not understand the corporate strategy and, in many cases, isn't even aware one exists. $\mathrm{He}$ claims that the lack of communication between upper and lower level managers results in decisions that are not consistent with the company's strategic direction. Thus, he proposes that basic requirements for performance management systems are following (Grady, 1991, p. 49-53):

1. The performance management system should include a set of measures that directly supports company strategies and provides diverse and balanced support. The performance measures must

6 J. F. Rockart (1979, p. 85) defined critical success factors to be: "the limited number of areas in which results, if they are satisfactory, will ensure successful competitive performance for the organization. They are the few key areas where "thing must go right" for the business to flourish. If the results in these areas are not adequate, the organization' effort for the period will be less than desired". 
provide all management levels with feedback on how well the strategies and objectives are being met.

2. Performance measures need to convey strategies and objectives through hierarchical and cross functional linkages. Hierarchical linkages provide feedback to goals or strategies at multiple levels of the organizations. On the other hand, strategies are cross functional therefore performance measures need to be cross functional as well.

3. Performance measures need to provide constant feedback at all management levels and functions of the business. The feedback ensures that top management's visions are translated to strategies and objectives for middle management and critical success factors and action plans for tactical management.

4. Performance measures need an external benchmark to evaluate feedback. Performance measurement needs to be included in the budgeting process and longer term business planning. Targets, both long-term and short-term, should be set by management with an eye on competitive performance.

5. Performance measures need to be balanced. Balance includes internal measures with external benchmarks, cost and non-cost measures, results measures to access the degree goals are achieved, and process measures to evaluate critical tasks and provide early feedback.

A. M. Ghalayini and J. S. Noble (1996, p. 77) have critically analyzed offered solutions and their limitations. On that basis it is possible to formulate the following criteria for selection and evaluation integrated performance measurement system:

- They should be constructed as improvement tools rather than monitoring and controlling tools. Thus, they need to explicitly consider the integration of continuous improvement.

- They need to provide a mechanism for specifying which objective should be met in a specific time horizon.

- They need to be dynamic systems and allow systematic revision of critical areas, performance measures, historical data, decisions and outcomes.

- They need to look ahead to predicting, achieving and improving future performance.

- They should stress the importance of global optimization versus local optimization and provide mechanism to achieve this. 
Nita, B.: Requirements for Performance Management Systems: A Delineation of the Comprehensice Set of Criteria.

- They need to stress the importance of time as a strategic performance measure.

- They need to provide a specific tool that could be used to model, control, monitor, and improve the activities at the factory level.

British authors, U. Bititci, A. Carrie and T. Turner (2006, p. 176-177), propose a long list of detailed characteristics for modern performance management systems. They claim that integrated performance measurement system should:

- reflect stakeholders requirements to maximize stakeholder satisfaction,

- reflect external/competitive position of an organization,

- focus on the competitive criteria of the organizations markets in order to facilitate strategies and actions to improve the competitive position of the organization,

- provide an input to strategy development,

- deploy strategic objectives through a logical path to business processes to ensure that strategy, actions, and measures are aligned,

- differentiate between control and improvement measures,

- focus on critical areas of the business to maximize the effect of the improvement effort,

- be expressed in a locally meaningful terminology to encourage understanding and maximize ownership,

- facilitate resource bargaining to ensure the provision of necessary resources to processes and activities critical to overall performance,

- facilitate intelligent and logical performance planning based on constraint management,

- promote proactive management by focusing on leading measures to facilitate a more proactive management style,

- accommodate both quantitative and qualitative measures,

- measure organizational capability and learning where appropriate,

- ensure that measures are used correctly,

- promote understanding of the casual relationships between various measures,

- facilitate simple reporting - demonstrating trends where possible,

- by dynamic and change in response to the changes in the internal and external environment of the organization. 
Academics from Belgium, S. Viaene and J. Willems (2007, p. 14-17), propose the set of six primary expectations set for corporate performance management:

1. The use of metrics - "you cannot manage what you cannot measure". This is equally true for the execution of organizational strategy. After the effective formulation of a strategy in clear objectives, the latter are to translated into critical success factors that are then linked into well chose performance metrics, so-called key performance indicators.

2. The use of a balanced set of performance metrics. It is a call for balancing short term and long term objectives, identified objectives and their underlying drivers, and hard, objective metrics and softer, more subjective ones.

3. The right-time delivery of actionable management information. In view of the massively available potentially interesting information floating around, highly efficient and effective filtering mechanisms are essential for supporting contemporary organizational management.

4. Horizontally integrated management. Aligning the value creation throughout the core enterprise processes, with a relentless focus on customer remains a fundamental organizational challenge. A lot of the traditional integrated organizational value chains are reconfiguring into value networks of outsourced core competences. This does complicate streamlining the management of all the value adding puzzle pieces.

5. Vertically integrated management. From a strategic management perspective this requires a clear articulation of the strategic objectives and underlying hypotheses. In order to be able to execute the chosen strategy, the objectives and hypotheses need to be mapped onto the tactical and operational levels to align them.

6. Closed loop management. The objective is to be and remain in control of the execution. Faced with constant, fast-paced change in the environment, mature management ought to be characterized by a capability for fast incremental learning as it continuously iterates through phases of planning, organization/execution and control. Moreover, there is the need for continuous synchronization of all three levels of management (strategic, tactical and operational).

The most comprehensive methodology for evaluation of performance management systems was proposed by M. Hudson, A. Smart and M. 
Nita, B.: Requirements for Performance Management Systems: A Delineation of the Comprehensice Set of Criteria.

Bourne (2001, p. 1009), who adopted several criteria and grouped them into three major sets:

1. requirements for performance management system development,

2. performance measures characteristics,

3. performance measurement dimensions (what is measured).

The first set of criteria includes account key users involvement, strategic objective identification, performance measure development, periodic maintenance structure, top management support, full employee support, clear and explicit objectives and set timescales.

\section{Comprehensive Set of Requirements}

Taking into account presented opinions of different authors as well as discussions from academic literature it is possible to synthesize these considerations. As a result it is proposed a comprehensive set of ten requirements that should be fulfilled by modern performance management systems:

1. linkage to organizational strategy,

2. focus on stakeholders,

3. multidimensional and balanced performance measurement,

4. allowing for critical success factors,

5. stimulation of organizational learning and continuous improvement,

6. performance reporting,

7. performance cascading,

8. orientation on future and planning,

9. serving as a control tool,

10. taking into account the motivational aspects.

Linkage to the organizational strategy means that performance management system should be complied with strategy and serve as a tool for strategy execution. Nowadays companies can choose among a wide variety of strategic analysis instruments, but the most important problem is concerned with strategy implementation. Thus, performance measures should be derived from strategy and allow to monitor its execution as well as to support management efforts toward achievement of future strategic goals. 
Focus on stakeholders involves taking into account demands and requirements of many groups interested in the company's activities. Performance management system should be designed in such a way that takes into account not only owners' interests, but also the needs of other groups such as clients, suppliers, and employees.

Multidimensional and balanced performance measurement comes from the notion that still a lot of companies today use financial and accounting-based calculations as the ultimate measures of company performance although exclusively financial approach to performance is not sufficient any longer. Thus, it is argued that under performance management it is needed to implement both financial and non-financial measures, both short-term and long-term measures, internal and external measures, objective and subjective metric as well as lagging and leading indicators.

Allowing for critical success factors involves the identification of special areas in a company critical form the point of view of company success and strategy execution. Obviously critical success factors may vary a great deal depending on the industry and the company itself (eg. delivery speed in an internet store or reliability in a car factory), but always it is needed to recognize these factors and quantify them by means of key performance indicators.

Stimulation of organizational learning means that performance management systems should be designed in such a way that all the employees can enhance their qualifications and organization as a whole is able to gain experience and increase the scope of knowledge as well as it is possible to increase the flexibility and innovation oriented toward gaining and sustaining competitive advantage. Continuous improvement of processes and activities run within an organization supports performance enhancement and strategy execution. Learning and continuous improvement make performance management system to be flexible and adaptable to changes in the external and internal environment. Performance management system cannot be treated as a static approach to management. The environment is changing all the time and thus the strategic assumptions must be modified and strategy should be challenged and systematically validated. In turn, the changes in strategy must trigger off the changes in performance management which is finally oriented toward strategy execution. 
Nita, B.: Requirements for Performance Management Systems: A Delineation of the Comprehensice Set of Criteria.

Performance reporting is an essential part of performance management, because without appropriate managerial reports it is not possible to take decisions and manage the organization with an eye on corporate performance improvement.

Performance cascading involves both vertical and horizontal cascading of objectives and measures. On the one hand it is worth considering performance measurement in different functional entities of the organization, on the other performance measures should be detailed at the lower levels in the organizational hierarchy.

Orientation on future and planning seems to be the natural characteristic of modern performance management system, because the planning function is a major function of management process. It is not possible to design modern performance management thinking solely about measurement assessment of past performance. Performance management involves approach to management oriented toward future that needs to consider the strategic directions and goal setting as well as obtaining resources essential for goal achievement.

Performance management should have the control sub-system that includes both feed-back and feed-forward loops. Feed-back loop provides managers with information about past performance, enables to compare it with expectations, derive the deviations from plan and finally to figure out conclusions that help to avoid the discrepancies in the future. Feedforward loop involves the anticipation of unfavorable deviations that are likely to happen and allows to made efforts in order to prevent them in the future.

The last requirement is associated with motivational function of management. Evaluation of performance of individual employees should be a basis for compensation programs that would stimulate employees to act in a manner that is consistent with the goals of the organization as a whole. Incentives in performance management are very important, because without appropriate orientation of employee behavior, by means of linking their salaries with the organizational goals, the strategy execution is hardly possible. 


\section{Conclusions}

Over the last two decades management accounting has been evolving very rapidly. Nowadays in highly competitive global market in order for organizations to gain, maintain and improve their competitive advantages a lot of management accounting techniques must be widely used. Modern approach to management accounting is associated with corporate performance management which not only focuses on measurement but also must be able to anticipate needed changes in the strategy. In this context performance measurement is an element of performance management and clearly indicates the strategic role of contemporary management accounting. Thus, it is reasonable to transform the approach to managerial accounting form management control to performance management. It is also justifiable to extend the scope of performance measurement that used to be the domain of management control, and perceive this concept as an integral part of performance management.

Contemporary management systems should fulfill a lot of requirements. Performance management involves constant monitoring and reporting the results achieved in different parts of the organization at all levels of the organizational hierarchy and across various functions, such as marketing, research and development, production etc. Performance management includes managerial reporting that provides concise, timely-based information on performance to managers. This information is needed in order to get insights in how the organization is really doing and what actions should be taken and how to do it. Performance management also includes compensation system design in such a way that managers and employees behave in a manner that is consistent with the goals of the organization and follow the organizational strategy. Performance management involves taking corrective actions if the actual performance is not in line with the expectations. This should be done by means of both feed-back and feed-forward loops. Finally, the process of performance management should challenge the strategy in order to confirm if the strategic assumptions remain valid. It involves considering and rethinking the actual strategy and, if needed, doing the changes in strategy that may have an impact on performance. By means of all the given components, performance management assures organizational learning and enables managers to improve the company performance. 
Nita, B.: Requirements for Performance Management Systems: A Delineation of the Comprehensice Set of Criteria.

\section{References}

[1] Anthony, R. N. (1965): Planning and Control Systems: A Framework for Analysis. Boston, Harvard Business School Press, 1965.

[2] Anthony, R. N. - Govindarajan, V. (2004): Management Control Systems. New York, McGraw-Hill, 2004.

[3] Beischel, M. E. - Smith, K. R. (1991): Linking the Shop Floor to the Top Floor. Management Accounting, 1991, vol. 73, no. 4, pp. 25-36.

[4] Bititci, U. - Carrie, A. - Turner, T. (2006): Integrated Performance Measurement Systems: Structure and Dynamics. In: Neely, A. (ed.): Business Performance Measurement. Theory and Practice. Cambridge, Cambridge University Press, 2006.

[5] Eccles, R. G. (1991): The Performance Measurement Manifesto. Harvard Business Review, 1991, vol. 69, no. 1, pp. 131-137.

[6] Ghalayini, A. M. - Noble, J. S. (1996): The Changing Basis of Performance Measurement. International Journal of Operations \& Production Management, 1996, vol. 16, no. 8, pp. 63-80.

[7] Grady, M. W. (1991): Performance measurement: implementing strategy. Management Accounting, 1991, vol. 72, no. 12, pp. 49-53.

[8] Hayes, R. H. - Abernathy, W. J. (1980): Managing Our Way to Economic Decline. Harvard Business Review, 1980, vol. 58, no. 4, pp. 138-149.

[9] Hudson, M. - Smart, A. - Bourne, M. (2001): Theory and Practice in SME Performance Measurement Systems. International Journal of Operations \& Production Management, 2001, vol. 21, no. 8, pp. 1096-1115.

[10] Johnson, H. T. - Kaplan, R. S. (1987): Relevance Lost. The Rise and Fall of Management Accounting. Boston, Harvard Business School Press, 1987.

[11] Kaplan, R. S. (1983): Measuring Manufacturing Performance: A New Challenge for Managerial Accounting Research. The Accounting Review, vol. 58, no. 4, pp. 686-703.

[12] Kaplan, R. S. (1984): The Evolution of Management Accounting. Accounting Review, 1984, vol. 59, no. 3, pp. 390-418. 
[13] Kaplan, R. S. - Norton, D. P. (1992): The Balanced Scorecard Measures that Drive Performance. Harvard Business Review, 1992, vol. 70, no. 1, pp. 71-79.

[14] Kaplan, R. S. - Norton, D. P. (1996): Using the Balanced Scorecard as a Strategic Management System. Harvard Business Review, 1996, vol. 74, no. 1, pp. 75-85.

[15] Kaplan, R. S. - Norton, D. P. (2001): Building a Strategy-Focused Organization. Ivey Business Journal, 2001, vol. 65, no. 5, pp. 12-19.

[16] Langfield-Smith, K. (1997): Management Control Systems: A Critical Review. Accounting, Organizations and Society, 1997, vol. 22, no. 2, pp. 207-232.

[17] Marr, B. - Gray, D. - Neely, A. (2003): Why do Firms Measure their Intellectual Capital? Journal of Intellectual Capital, 2003, vol. 4, no. 4, pp. 441-464.

[18] Maskell, B. (1989): Performance Measurement for World Class Manufacturing. Management Accounting, 1989, vol. 67, no. 5, pp. 32-33.

[19] Otley, D. (1999): Performance Management: A Framework for Management Control Systems Research. Management Accounting Research, 1999, vol. 10, no. 4, pp. 363-382.

[20] Rappaport, A. (1981): Selecting Strategies That Create Shareholder Value. Harvard Business Review, 1981, vo. 59, no. 3, pp. 139-149.

[21] Rappaport, A. (1986): Creating Shareholder Value. New York, Free Press, 1986.

[22] Rockart, J. F. (1979): Chief Executives Define Their Own Data Needs. Harvard Business Review, 1979, vol. 57, no. 3, pp. 81-93.

[23] Schonberger, R. J. (1986): World Class Manufacturing: The Lessons of Simplicity Applied. New York, Free Press, 1986.

[24] Simmonds, K. (1981): Strategic Management Accounting. Management Accounting, 1981, vol. 59, no. 4, pp. 26-30.

[25] Viaene, S. - Willems, J. (2007): Corporate Performance Management: Beyond Dashboards and Scorecards. Journal of Performance Management, 2007, vol. 20, no. 1, pp. 13-32. 


\title{
Requirements for Performance Management Systems: A Delineation of the Comprehensive Set of Criteria
}

\author{
Barttomiej NITA
}

\begin{abstract}
The paper deals with the problem of identification of the requirements that should be ful-filled by modern corporate performance management systems. In the first part of the article the essence of corporate performance management was depicted very briefly taking into ac-count the evolution of management accounting. Next, the overview of different ideas on the subject was presented and some opinions taken from literature were discussed. On this basis the original and comprehensive set of criteria treated as the requirements for performance management systems was proposed.
\end{abstract}

Key words: Management accounting; Performance management.

JEL classification: M41. 